\title{
Determination of an effective pollinator for the rare and endangered Urophysa rochkii and the effects of its floral organs on flower visiting by insects
}

\author{
Pengfei Bie, Ting Tang, Jinyao Hu*, Lushui Zhang and Qiuyue Zhao \\ Key Laboratory of Ecological Security and Protection of Sichuan Province, Eco Environmental Engineering Technology Research Center, \\ College of Life Science and Technology, Mianyang Normal University, Mianyang 621000, China
}

Pollination is an important part of fertilization and reproduction in seed plants. Pollen movement largely restricts gene flow among individual plants and the manner of reproduction in a population, thereby affecting the genetic traits and fitness of plant offspring. For insect-pollinator-based plants, the flower-visiting characteristics, frequency and timing of the pollinating insects have decisive effects on the successful pollination of plants, whereas the colour and morphology of various floral components are important factors affecting the pollinating insects. Based on the pollination biology of plants, we studied the pollination mechanisms and links of Urophysa rochkii to understand its endangered status. Using $U$. rochkii at the full flowering period for the study, and using methods to observe, record, and perform experimental analysis, we recorded the species, frequency and flowervisiting time of these insects every $15 \mathrm{~min}$ and observed the effects of weather and temperature on the insects. Additionally, we captured the flowervisiting insects, brought them to the laboratory, and took photographs under a dissecting electron microscope for observation and identification. $U$. rochkii plants were grouped under different treatments that included removal of sepals, stamens and or pistils, while untreated plants were included as control group. In summary, the effects of floral components on the pollination process were examined. The experimental results showed that the effective pollinator of $U$. rochkii was Apis cerana Fabricius, and that sky-blue sepal was the most important factor affecting the flowervisiting frequency of the pollinators.

Keywords: Pollination biology, flower-visiting insects, floral organs, Urophysa rochkii.

POLLINATION is a fundamental and important process in plant breeding systems and ecosystem functioning ${ }^{1}$. It also plays an important role in plant diversity ${ }^{2}$. Most plants have bisexual flowers, with the peculiarities of

*For correspondence. (e-mail: 250563963@qq.com) flower types increasing the output of pollen grains (stamens) and its reception (stigma) $)^{3}$. Approximately $90 \%$ of flowering plants are insect pollinator-based ${ }^{4}$. In addition to achieving pollination by taking advantage of animals, plants can also use water and wind for pollen transport during pollination ${ }^{5-7}$. For insect pollinator-based plants, the behaviour of the pollinators and the plant breeding system are influenced by multiple plant characteristics ${ }^{8,9}$, including flower morphological characteristics and biological phenological characteristics ${ }^{10}$, selfincompatibility and inflorescence structure ${ }^{11}$. The floral features not only promote pollination efficiency but also limit the flower-visiting frequency of ineffective flowervisiting insects ${ }^{12}$, thereby avoiding 'wastage' of pollen grains $^{13}$. For example, in Syringa oblata Lindl, the white sepals and blue corolla form a strong contrast, which plays a role in attracting pollinators ${ }^{14}$.

The flowering biological characteristics, plant flower number and flower arrangement pattern affect breeding systems $^{8,11}$. For example, while an increase in flower number in plants would enhance the attraction of pollinators, it may also result in more self-pollination in the same plant ${ }^{10,15}$. The establishment of a new environment for a plant population may lead to significant changes in its floral characteristics and mating system, especially if pollinators are scarce ${ }^{16}$. For endangered plants in fragmented habitats, a small number of individuals within a population is not conducive to effectively attract pollinators, and the fragmented habitat may also affect the survival of pollinators per se. Therefore, the interaction between plants and pollinators may be blocked ${ }^{17,18}$, and the resultant pollen limitation may further affect the reproductive success of the plants ${ }^{19}$. With changes in human habitat and climate, the stability of pollination systems is being threatened ${ }^{20,21}$, the number of plant populations and pollinators is decreasing ${ }^{22}$, and the seasonal mismatch between plants and pollinators is increasing ${ }^{23-25}$. Under natural conditions, due to the effects of climatic and environmental factors, pollinating insects for some plants have low flower-visiting frequency or carry insufficient pollen, but these insects could increase their 


\section{RESEARCH ARTICLES}

pollination efficiency through other mechanisms. For example, in a field study, Herrera et al. ${ }^{26}$ observed that although insects visited Helleborus foetidus L. (Ranunculaceae) at a very low frequency, its seed-setting rate was not affected by prolonging its flowering period to increase pollination efficiency.

To date, studies on Urophysa rochkii have been limited to its genetic diversity ${ }^{27,28}$, seed distribution ${ }^{29}$, soil physico-chemical properties and biological characteristics of communities as well as to biological and ecological aspects, such as the community characteristics of its habi$\operatorname{tat}^{30}$. However, no studies have been made on its productive ecology, such as that observed with the pollination ecology of $U$. rochkii. In this study, we explored whether the $U$. rochkii flower can effectively attract enough pollinating insects and the effect of each floral organ on attracting flower visitors. To develop reasonable protective measures and provide adequate and reasonable theoretical bases, we addressed the following two issues: (1) Which insects are the main pollinators in the flowering period of $U$. rochkii and which of them are most effective? (2) What are the main factors that attract insects in the pollination process?

\section{Materials and methods}

\section{Research background}

Urophysa rochkii Ulbr. is a plant species belonging to the genus Urophysa family Ranunculaceae. It is an endemic species, with only a small distribution in the upper reaches of the Fujiang River in Jiangyou City, Sichuan Province, China. In 1925, an American plant collector, J. F. Rock, found this species in Jiangyou, for the first time and collected a sample. In 1929, Ulbrich ${ }^{31}$ published a paper on this species (Figure 1).

Here, Xiangjiagou, Yongsheng Township was selected as the study site (Figure 2). The geographical location of the study site is $31^{\circ} 59^{\prime} 14.6^{\prime \prime} \mathrm{N}, 104^{\circ} 51^{\prime} 01.8^{\prime \prime} \mathrm{E}$; it has a slope of $85^{\circ}$, a northwest aspect of $20^{\circ}$ and an elevation of 910-970 m. This area belongs to the subtropical monsoon climate zone and has the climatic characteristics of warm winter and early spring, long summer and short winter, and a long frost-free period, as well as abundant rainfall. It has four distinct seasons, with summer and rainy seasons co-occurring and exhibiting obvious geographical changes. $U$. rochkii grows in relatively humid places on limestone cliffs in the middle of the mountains, accompanied mainly by Adiantum capillus-veneris L., Gelsemium elegans (Gardner and Champ.) Benth., Primula malacoides Franch, and Epimedium davidii Franch. In the study location, $U$. rochkii has a clustered distribution $^{32}$.

The petals pacing characteristics in $U$. rochkii flowers have important scientific value for establishing phylo- geny within the Aquilegia taxa of family Ranunculaceae. $U$. rochkii plays an important role in plant taxonomy and in the genetic protection of rare plants. This species is rich in aromatic lipids, and the colours of the petals and leaves change over time. It has a long flowering period (usually from December to April) and is thus a winterflowering plant, providing the species with potential medicinal and ornamental value ${ }^{33}$.

\section{Flowering process and floral characteristics of U. rochkii}

During the bud stage in December 2011 and December 2012, we randomly selected 50 U. rochkii plants from different populations for labelling, with flower shape, size, colour and spatio-temporal dynamics being recorded (while noting to the positions of stigma and anther). After the full blossom stage, 50 flowers were randomly selected and the major floral morphological indices, such as

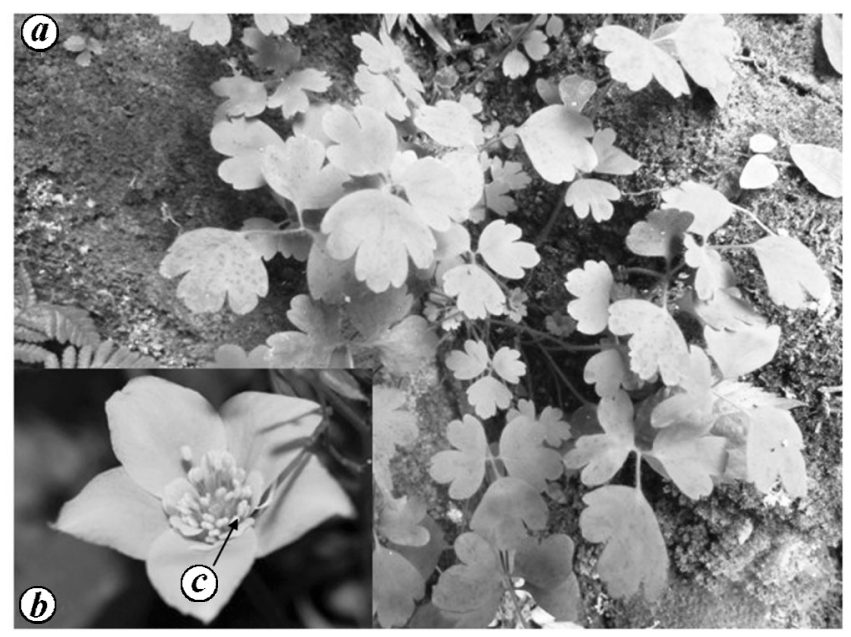

Figure 1. a, Urophysa rochkii Plant, b, Flower; $\boldsymbol{c}$, Anther. Arrow denotes groove in the ventral surface of the anthers.
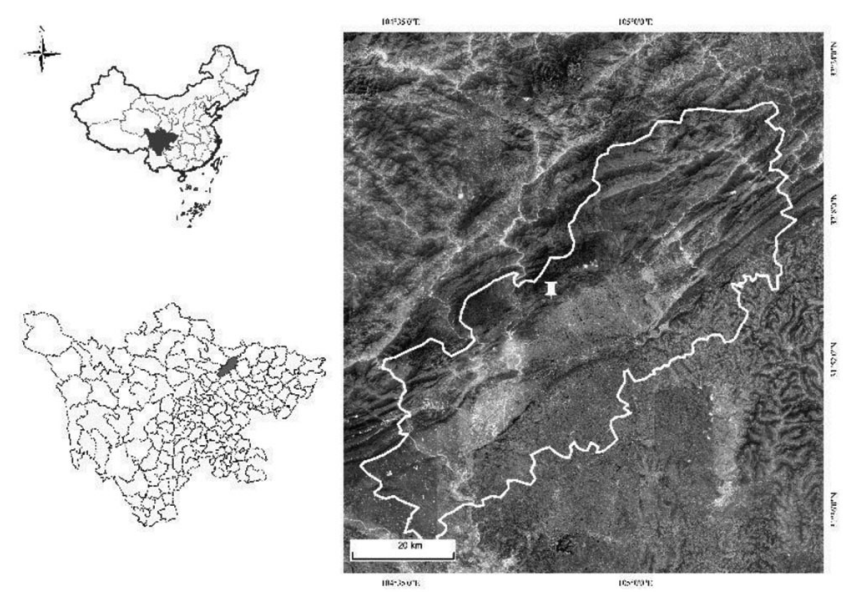

Figure 2. Location of study site and $U$. rochkii morphology. 
sepal length, petal length, anther length and style length were measured with a Vernier caliper, and the floral were recorded.

In addition, according to the criteria of Dafni ${ }^{34}$, the flowering process of $U$. rochkii populations at the observation site was described, and initiation times were recorded for (i) beginning of the flowering stage; (ii) when less than $25 \%$ of the plants were in the flowering stage; (iii) when more than $50 \%$ of the plants were in flowering stage; (4) when less than $25 \%$ of the plants were in the flowering stage while the remaining flowers were withering, and (5) late flowering (when less than $10 \%$ of the plants were still in the flowering stage).

\section{Observation and identification of flower-visiting insects}

During the flowering period, 50 flowers with robust growth were selected for observation. With every $15 \mathrm{~min}$ considered as a statistical unit, the species of flowervisiting insects were recorded (and photographs taken), and the visiting time and temperature when the insects visited were recorded. Flower-visiting insects were captured, and individuals used for species identification were fixed in 50\% alcohol and photographed for observation and identification under a dissecting electron microscope.

\section{Effects of weather on flower-visiting insects}

Temperature and weather conditions are factors that affect insect visitation. At the full flowering stage, for 30 labelled flowers, we collected statistics on the flower visiting behaviour of insects at the same time under different weather conditions. Table 1 shows the observed weather conditions and temperature.

\section{Effects of floral organs on insect pollination}

Flowers are important in plant breeding: To determine the effects of sepals, stamens and pistils on the pollinator

Table 1. Temperature and weather conditions during the Urophysa rochkii flowering period

\begin{tabular}{cclc}
\hline Year & Date (month, day) & Weather & Temperature $\left({ }^{\circ} \mathrm{C}\right)$ \\
\hline 2012 & 3,7 & Sunny & $6-12$ \\
& 3,8 & Sunny & $6-12$ \\
3,9 & Cloudy & $5-10$ \\
3,1 & Rain & $3-10$ \\
3,11 & Sunny & $6-12$ \\
3,12 & Sunny & $6-13$ \\
3,13 & Sunny & $8-15$ \\
3,14 & Cloudy & $10-17$ \\
3,15 & Cloudy & $10-18$ \\
3,16 & Sunny & $11-18$ \\
\hline
\end{tabular}

insects and on the pollination process, four groups of treatment were included in the field: with sepals removed (Group A, 50 flowers), with stamens removed (Group B, 50 flowers), with pistils removed (Group C, 50 flowers), and control group (Group D, 50 flowers). Each individual was labelled with a tag. In the full flowering period, 15 flowers were selected from the treated flowers in each group for observation. For five consecutive days, the flower-visiting behaviour of the insects was observed each day from $08: 00$ to $18: 00 \mathrm{~h}$, with every hour serving as a statistical unit. The insect visiting number was recorded by separate groups, and all data from the five days were averaged and considered as the flower-visiting frequency of the insects for each treatment. Next, each group/treatment was maintained until the flowers withered and seeds were set, and data on seed-setting rate for each group were recorded.

\section{Results}

\section{U. rochkii flowering process and floral organ statistics}

Four to five days after the emergence of $U$. rochkii buds, the sepals opened one after another. The opening of the first sepal of each flower marked the beginning of the flowering period for that flower. In the first 2-3 days of the flowering period, the stigmas were at a higher position than the anthers for all 50 flowers under observation. With the progression of observation time, filaments of $U$. rochkii continued to elongate. In the 4 th-6th day of the flowering period, 21 flowers had elongated filaments, and their anthers were significantly higher than the stigmas, whereas the remaining 29 flowers still had stigmas higher than the anthers. In the following days, the filaments of the 29 flowers gradually elongated. On the 10th day of the flowering period, the anthers were higher than the stigmas for all 50 flowers, and half of the flowers began to wither. Field measurements showed the diameter of $U$. rochkii flowers was $19.26 \pm 2.80 \mathrm{~mm}$ (mean $\pm \mathrm{SD}$ ). Table 2 shows the statistical results for the number and length of floral organs for the $50 \mathrm{U}$. rochkii flowers.

According to field experiments in 2011 and 2012, $U$. rochkii withered in summer, began to revive and grow in early August, and formed flower buds in early October. The flower buds emerged and gradually enlarged in early December, and the duration of this process was relatively long, usually approximately one month. Plants then underwent the stages of flowering and withering, until most of the flowers had withered, which marked the end of the flowering phenology. The flowering phenology of $U$. rochkii extended from early December of the first year to middle or late April of the second year. Fruiting started in late March; in early June, the fruits ripened, the pericarp split and the seeds were released. 
Table 2. Maximum and minimum length, and average (SD) length of floral organs, as well as maximum and minimum number and average number of flower organs in each flower of $U$. rochkii

\begin{tabular}{lccccccc}
\hline Origin & $N$ & $\begin{array}{c}\text { Maximum } \\
\text { length }\end{array}$ & $\begin{array}{c}\text { Minimum } \\
\text { length }\end{array}$ & $\begin{array}{c}\text { Length } \\
\text { (mean } \pm \text { SD) }\end{array}$ & $\begin{array}{c}\text { Maximum number } \\
\text { in a single flower }\end{array}$ & $\begin{array}{c}\text { Minimum number } \\
\text { in a single flower }\end{array}$ & $\begin{array}{c}\text { Average number } \\
\text { in a single flower }\end{array}$ \\
\hline Calyx & 252 & 30.99 & 16.04 & $22.89 \pm 3.39$ & 6 & 5 & 5.04 \\
Petal & 255 & 9.95 & 5.85 & $7.71 \pm 0.79$ & 7 & 5 & 3.1 \\
Anther & 250 & 2.33 & 0.81 & $1.57 \pm 0.27$ & 50 & 4 & 4.8 \\
Style & 244 & 11.21 & 4.35 & $7.56 \pm 1.24$ & 6 & 4 \\
\hline
\end{tabular}
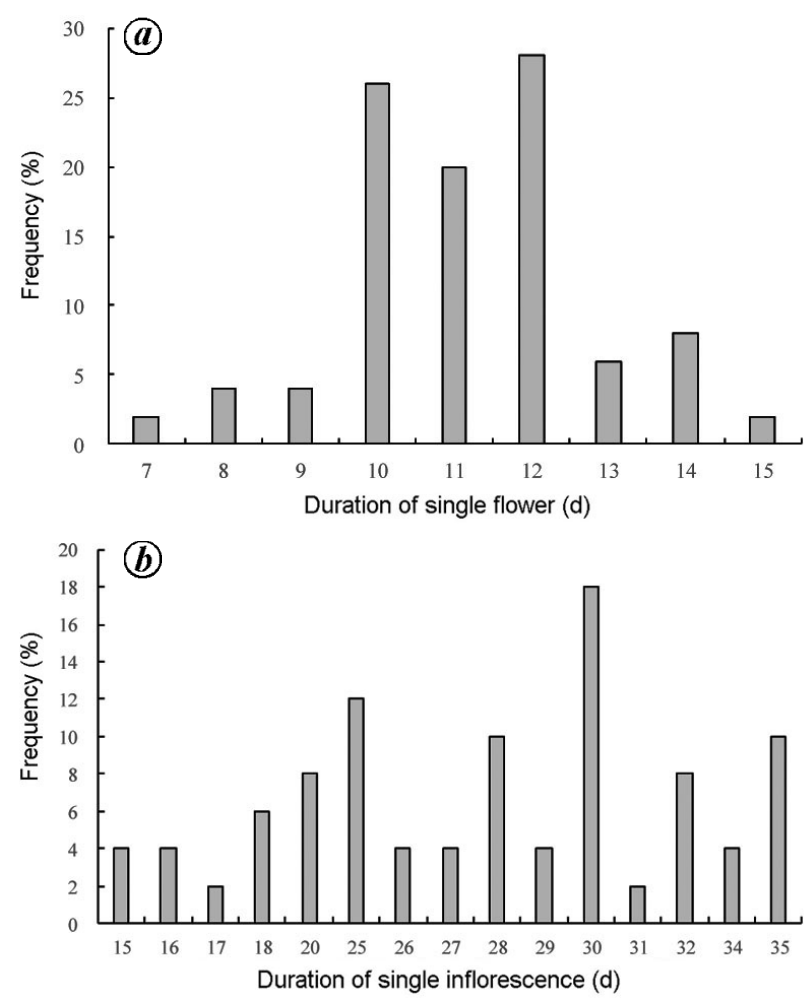

Figure 3. Frequency of flowering duration of a single flower and inflorescence of $U$. rochkii. (a) Frequency distribution of single flower longevity. (b) Frequency distribution of inflorescence longevity.

Our phenological observations on $U$. rochkii showed that the flowering of single flowers did not have a fixed time. The flowering duration of single flowers had a range of $7-15 \mathrm{~d}$, with $12 \mathrm{~d}$ showing the highest frequency (Figure 3), and the average flowering time of a single flower was $11.18 \pm 1.64 \mathrm{~d}$ (ref. 32). In the bud stage, the sepals were often light green or light purple, and flowers on the inflorescence occurred in an alternating manner. When the flowers had opened, the sepals expanded one after the other, and their colour changed from light green to white or sky blue (light purple); generally, flowers at the top of the same inflorescence were the first to open. On sunny days, the buds opened mostly around noon, which may be related to air temperature on the day of flowering.

Bisexual flowers are borne on cymose inflorescences. There are usually 4-22 inflorescences in each plant, with
2-4 flower buds on each inflorescence in an alternating manner. Inflorescence phenology is related to the spatial location of the on the flower branch. The flowering period of a single-flower inflorescence was approximately 15-35, with the highest frequency being $30 \mathrm{~d}$ (Figure 3) and the average being $26.78 \pm 5.93 \mathrm{~d}$.

When the flowers had opened, the stigmas were at a significantly higher position than the anthers. The styles did not elongate significantly during the flowering period, whereas the filaments began to elongate on the flowering day or on the second day until the anthers began to crack to release the pollen. Among all filaments, those in the inner whorls elongated first, and the anthers on these filaments shed their pollen.

\section{Flower-visiting insects and their behaviour}

Observe 50 flowers between $11: 00-14: 00$ every day, observe and statistics 4 times, 15 min each time, record the number of visits to a flower, observe 5 days continuously, take average as an insect visiting frequency. The flower-visiting insects of $U$. rochkii included three orders: Diptera (Muscidae; Culicidae), Hymenoptera (Apoidea; Formicidae), and Homoptera (Aphidae; Psyllidae), which totaled five species. Among them, only Mitroplatia sp. of the order Diptera, Apis cerana Fabricius of the order Hymenoptera, and Myzus persicae of the order Homoptera were accurately identified, whereas other insects could not be identified at the species level due to research limitations (Figure 4). The flower-visiting insects of $U$. rochkii mainly had two body types: one was medium-sized, such as Myzus sp. and A. cerana Fabricius, while the other was small-sized, such as $M$. persicae.

The flower-visiting frequency varied greatly among the different insect species. The flower-visiting frequency of A. cerana Fabricius was significantly higher than that of other insects, while the flower-visiting frequency of Myzus sp. was almost the same as M. persicae. Within $15 \mathrm{~min}$, a flower was visited $1.65 \pm 0.33,0.72 \pm 0.024$, and $0.73 \pm 0.024$ times on average by $A$. cerana Fabricius, Mitroplatia sp. and $M$. persicae respectively. In contrast, the visiting frequencies of Culicidae, Formicidae and Psyllidae insects were low, and less than 0.15 times. We observed that the active time of flower-visitors of $U$. rochkii was during $11: 00-14: 00 \mathrm{~h}$ (Figure 5). 
The effective pollinator of $U$. rochkii was $A$. cerana Fabricius. The insects of this species stayed on the flowers for approximately 5-10 sec, mainly to feed and collect pollen or nectar. They hovered around the inflorescences to look for targets, mostly flowers with cracking anthers. They firmly captured the filaments with their forelegs and held the stamens with their middle and hind legs; in this position, their tails were slightly raised so that the stamens of $U$. rochkii were close to the abdomens of the insects. In the pollen feeding process, they constantly turned their bodies around the stamens to ensure high pollen collection. They scraped the pollen with their middle and hind legs, with the scraped pollen grains falling close to their abdomens (Figure $6 a-d$ ).

The species of flower-visiting insects of $U$. rochkii were relatively few, and the number was relatively small. When an electronic microscope was used to detect flower-visiting insects, only the head, thorax, abdomen and feet of $A$. cerana Fabricius carried a large number of pollen grains, indicating that this species can play a key role in pollination, and is an effective pollinator. Observations of several other flower-visiting insects showed that they carried no pollen grains.

\section{Effects of weather on flower-visiting behaviour of insects}

Insects visit $U$. rochkii flowers in two ways: flying directly to the flowers on sunny days, and climbing along the

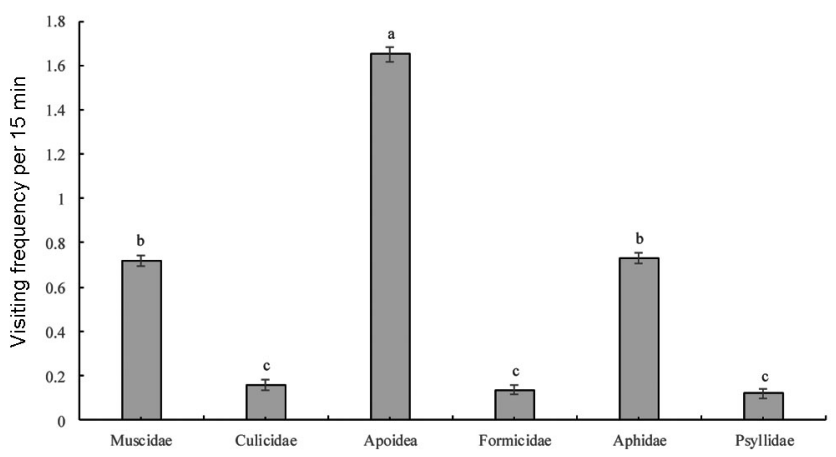

Figure 4. Visiting frequency (mean $\pm \mathrm{SE}$ ) of insects.

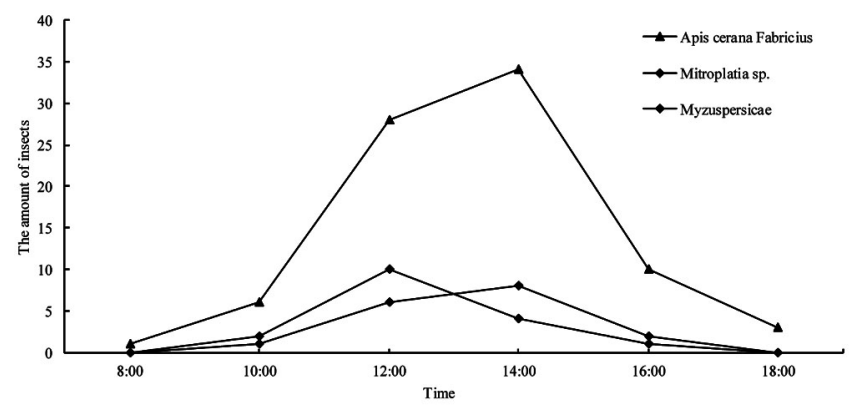

Figure 5. Visiting time of different insects (a - Apis cerana Fabricius; b-Mitroplatia $\mathrm{sp}$; $\mathrm{c}-$ Myzus persicae). pedicel to the flower surface and resting on the sepals on cloudy or rainy days. Flower-visiting insects feed on nectar by moving among the flowers, and in the process, pollen particles stick to their head, tentacles and feet, thus increasing pollination efficiency. Field observations showed that the flower-visiting times of insects changed significantly with change in temperature. The time insects spent visiting flowers increased with increase in the ambient temperature. No flying insects were observed when the air temperature was below $8^{\circ} \mathrm{C}$; at these times, the insects usually slowly crawled upward along the pedicels and hid themselves under the sepals or stayed on the leaves. Therefore, the behaviour of stationary insects directly affects pollination efficiency, which is lower than that of volitant insects.

Weather condition is another factor that affects flower visiting by insects. The time that insects spent visiting flowers on sunny days was more than that on rainy days. Between 12:30-13:00 in from 7-16 March 2012, a continuous observation of $30 \mathrm{U}$. rochkii flowers for 10 days, Statistics of the number of Volitant insects and Quiescent insects, 6 days are sunny, 3 days are cloudy, and the 1 day is rainy. The frequency of flower visits by insects on sunny days was significantly higher than that on rainy days (Figure 7). On clear days, A. cerana Fabricius, M. persicae, and Myzus sp. visited the flowers, and moved among them searching for food (Figure $6 a-g$ ). On rainy days, $A$. cerana Fabricius was nearly inactive, while $M$. persicae and Myzus sp. remained at the back of the leaves of the plant for a long time (Figure $6 f$ ).

\section{Effects of floral organs on insect pollination}

According to experimental observations and statistical data analysis, the flower-visiting frequency of $U$. rochkii showed the following ascending order of groups: A (with sepals removed) $<\mathrm{B}$ (with stamens removed) $<\mathrm{C}$ (with pistils removed) $<\mathrm{D}$ (control) (Figure $8 a$ ). The control group had the most species of flower-visiting insects and highest frequency of flower visiting. There was significant difference between the group with sepals removed and that with stamens removed $(P<0.05)$. When the stamens and pistils were removed from the flowers, the flower-visiting insect species of both groups were slightly different from those of the control group. The flowervisiting frequencies of the two groups were reduced compared with that of the control group. Additionally, with the sepals removed, the flower-visiting insect species and the flower-visiting frequency were lowest: the main flower visitor was $A$. cerana Fabricius; it stayed on the stamens only for a short time. These results indicate that the attractiveness of floral organs to visiting insects follows the descending order: sepals $>$ stamens $>$ pistils.

The seed-setting rate of each group also decreased compared with the control group (Figure $8 b$ ). The 


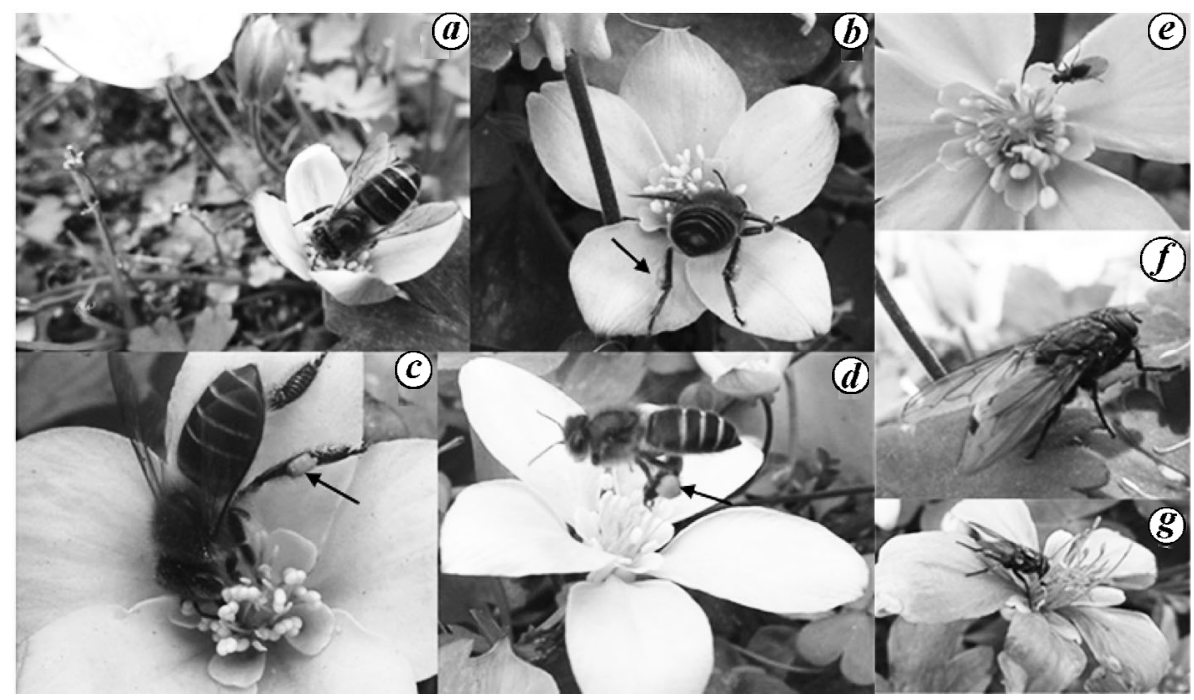

Figure 6. Flower-visiting activities of insects. $\boldsymbol{a}-\boldsymbol{d}$, A cerana Fabricius visiting $U$. rochkii flowers. The insects move around the stamen (arrow showing a large number of pollen grains adhering to the hind legs of $A$. cerana Fabricius). (e) A Formicine insect visiting $U$. rochkii flower. $\boldsymbol{f}-\boldsymbol{g}$, Mitroplatia sp. visiting a U. rochkii flower. ( $\boldsymbol{f}$ ) Myzus sp. resting on the leaf surface. (g) Myzus sp. visiting a nearly withered flower.

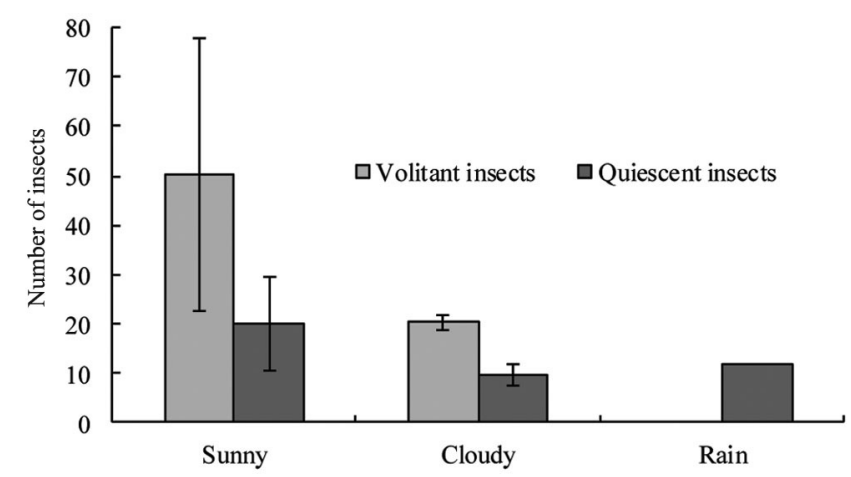

Figure 7. Flower-visiting of insects (mean \pm SD) during different weather conditions.

seed-setting rate showed the following ascending order of groups: A (with sepals removed) $<\mathrm{B}$ (with stamens removed) $<\mathrm{D}$ (control). No seed setting occurred for $U$. rochkii when the pistils were removed.

\section{Discussion}

\section{$U$. rochkii flowering process and integrated pollination characteristics}

Observations on the flowering phenology of $U$. rochkii showed that the flowering period was relatively long, generally extending from early December in a particular year to mid-April of the following year. The plant had a long flowering period and exhibited an obvious flowering asynchrony. At the single-flower and single-inflorescence levels, a single flower had a flowering duration ranging from 8 to $15 \mathrm{~d}$, with a single plant having flowering duration lasting approximately two months; a population could have flowering duration lasting approximately four months. The long duration of flowering and asynchronized flowering not only ensures a sufficiently long time for the plants to successfully complete pollination and fertilization, but also reduces the negative effects of an adverse natural environment during the flowering period on the reproductive success of the plant. This is a reproductive strategy that $U$. rochkii has developed in its longterm adaptation to environmental impacts.

Ranunculus is one of the base groups of angiosperms $^{35,36}$. Previous studies have shown that plants offer various forms of reward for pollinating insects, with the most common ones being pollen, nectar, or both ${ }^{37,38}$. The sky-blue sepals and yellow, uncracked anthers of $U$. rochkii display a significant visual contrast in their colour. Anthers crack and expose a large number of pollen grains, which can provide food for some flower-visiting insects. Therefore, sepals, stamens, pistils and the rewards that they provide together constitute the pollination characteristics of $U$. rochkii.

\section{Flower-visiting behaviour of insects to $U$. rochkii}

The frequency and mutual effects of the interaction between flower visitors and the flowers jointly determine the effectiveness of pollination ${ }^{39-41}$. The identification of an effective pollinating insect isan important aspect for understanding the characteristics of reproductive biology; it is also a prerequisite for understanding why a species is rare and endangered ${ }^{42}$. The present study demonstrates 

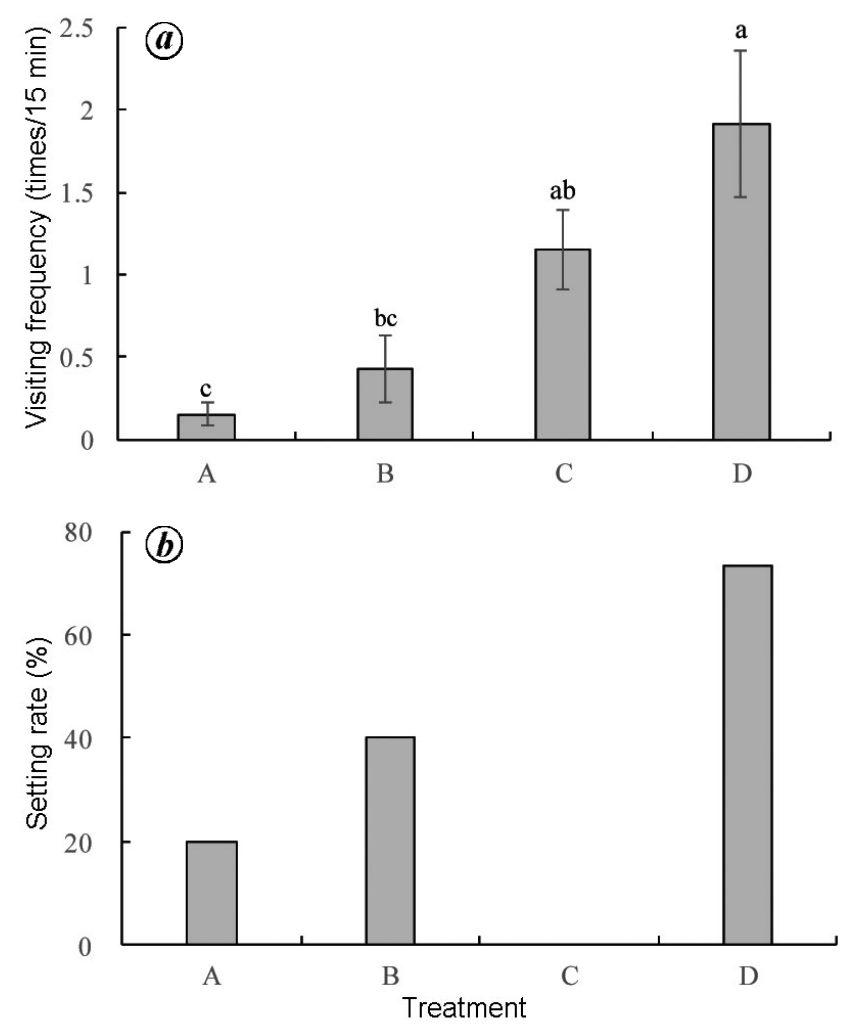

Figure 8. $\boldsymbol{a}$, Visiting frequency of insects after different treatments. b, Comparison of seed setting after different treatments in U. rochkii. A - Sepals removed. B - Stamens removed. C - Pistils removed. D Control.

that the effective pollinator of $U$. rochkii is $A$. cerana Fabricius, while other insects do not carry pollen grains and thus do not play a role in pollination even though they visit the flowers.

The amount of pollen dispersal and nectar secretion of plants are synergistic with pollinating insects in time. The peak period of pollination visits corresponds to the time of pollen dispersal and nectar secretion ${ }^{43}$. We found that under sunny conditions, the $U$. rochkii anthers cracked mostly during $11: 00-14: 00$. As the number of cracking anthers increased, the amount of pollen being dispersed increased, with substantial reward being provided to the insects. On the other hand, experimental results show that the active time of flower-visiting insects is also $11: 00$ $14: 00$, which is consistent with the time of anther cracking.

\section{Effects of floral organs on pollination by flower-visiting insects}

The floral organ that most readily undergoes evolution in Ranunculaceae plants is the petal ${ }^{44}$. The petals of $U$. rochkii show no obvious differentiation and have no obvious attraction to insects, which may be one of the reasons for the endangered status of the plant.
For bio-pollinated plants, the floral characteristics are evolutionarily related to the pollination system and have the most direct effects on attracting pollinators ${ }^{45}$. For insect pollinator-based plants, flower colour, corolla structure, and the existence of odours directly affect the pollination efficiency ${ }^{46}$. U. rochkii has multiple stamens and its petals secrete nectar. Therefore, its flower is typical of an insect-pollinated plant. The most important signal in the pollination system is the sense of sight, and bright flower colour can have a visual impact on the pollinators ${ }^{47}$. The sepals of $U$. rochkii account for a large proportion of the entire flower; the colour contrast between the sky-blue sepals and the yellow petals and anthers can visually attract pollinators to the flowers and provide a resting platform for the insects. With sepals removed in $U$. rochkii, the flower-visiting frequency of insects per flower was 0.1553 times/min, which was significantly lower than that of the groups with the stamens and pistils removed as well as the control group. In $U$. rochkii, seed-setting rate for the treatment group with sepals removed was only $20 \%$, which was lower than that for the group with stamens removed (40\%) group and significantly lower than that for the control group (70\%). The seed-setting rate for the group with pistils removed was 0 , indicating that no apomixis occurred. Therefore, we conclude that the sky-blue sepal is the most important factor for attracting insects to the flowers.

1. Klinkhamer, P., Plant-pollinator interactions: from specialization to generalization. Ann. Bot., 2006, 98, 899-900.

2. Khors, Rosa, R. and Koptur, S., New findings on the pollination biology of Mauritia flexuosa (Arecaceae) in Roraima, Brazil: Linking dioecy, wind, and habitat. Am. J. Bot., 2013, 100(3), 613621.

3. La Rosa, R. J. and Conner, J. K., Floral function: effects of traits on pollinators, male and female pollination success, and female fitness across three species of milkweeds (Asclepias). Am. J. Bot., 2017, 104, 150-160.

4. Ollerton, J., Winfree, R. and tarrant, How many plants are pollinated by animals? Oikos, 2011, 120, 321-326.

5. Cox, P. A. and Grubb, P. J., Abiotic pollination: an evolutionary. escape for animal-pollinated angiosperms (and discussion). Philos. Trans. R. Soc. London, Ser. B, 1991, 333, 217-224.

6. Proctor, M., Yeo, P. and Lack, A., The Natural History of Pollination, Portland, Timber Press, Ohio, USA, 1996.

7. Thien, L. B., Azuma, H. and Kawano, S., New perspectives on the pollination biology of basal angiosperms. Int. J. Plant Sci., 2000, 161, S225-S235.

8. Wyatt, R., Inflorescence architecture: how flower number, arrangement, and phenology affect pollination and fruit-set. Am. J. Bot., 1982, 69, 585-594.

9. Richards, A. J. and Holsinger, K. E., Plant breeding systems. Trends Plant Sci., 1997, 2, 485-485.

10. Harder, L. D. and Barrett, S. C., Pollen dispersal and mating patterns in animal-pollinated plants. Floral Biology, 1996, 140-190.

11. Williams, C. F., Ruvinsky, J. and Hews, S. D. K., Pollination, breeding system, and genetic structure in two sympatric Delphinium (Ranunculaceae) species. Am. J. Bot., 2001, 88(9), 16231633.

12. Muchhala, N., The pollination biology of Burmeistera (Campanulaceae): specialization and syndromes. Am. J. Bot., 2006, 93, 1081-1089. 
13. Thomson, J. When is it mutualism? Am. Nat., 2003, 162, S1-S9.

14. Hobbhahn, N., Küchmeister, H. and Porembski, S., Pollination biology of mass flowering terrestrial Utricularia species (Lentibulariaceae) in the Indian Western Ghats. Plant Biol., 2006, 8(6), 791-804.

15. De Jong, T. J. D., Waser, N. M. and Klinkhamer, P. G., Geitonogamy: the neglected side of selfing. Trends Ecol. Evol., 1993, 8(9), 321-325.

16. Brys, R., Geens, B., Beeckman, T. and Jacquemyn, H., Differences in dichogamy and herkogamy contribute to higher selfing in contrasting environments in the annual Blackstonia perfoliata (Gentianaceae). Ann. Bot., 2013, 111(4), 651-661.

17. Kearns, C. A. and Inouye, D. W., Endangered mutualisms: the conservation of plant-pollinator interactions. Annu. Rev. Ecol. Syst., 1998, 29(1), 83-112.

18. Moody-Weis, J. M. and Heywood, J. S., Pollination limitation to reproductive success in the Missouri evening primrose, Oenothera macrocarpa (Onagraceae). Am. J. Bot., 2001, 88, 1615-1622.

19. Ashman, T. L., Knight, T. M., Steets, J. A., Amarasekare, P. and Wilson, W. G., Pollen limitation of plant reproduction: ecological and evolutionary causes and consequences. Ecology, 2004, 85(9), 2408-2421.

20. Dupont, Y. L., Damgaard, C. and Simonsen, V., Quantitative historical change in bumblebee (Bombus spp.) assemblages of red clover fields. PLOS ONE, 2011, 6, e25172.

21. Bommarco, R., Lundin, O., Smith, H. G., and Rundlöf, M., Drastic historic shifts in bumble-bee community composition in Sweden. Proc. R. Soc. B: Biol. Sci., 2012, 279(1727), 309-315.

22. Biesmeijer, J. C., Parallel declines in pollinators and insectpollinated plants in Britain and the Netherlands. Science, 2006, 313, 351-354

23. Doi, H., Gordo, O. and Katano, I., Heterogeneous intra-annual climatic changes drive different phenological responses at two trophic levels. Climate Research, 2008, 36(3), 181-190.

24. McKinney, A. M., Asynchronous changes in phenology of migrating Broad-tailed Hummingbirds and their early-season nectar resources. Ecology, 2012, 93, 1987-1993.

25. Pyke, G. H., Thomson, J. D., Inouye, D. W., Miller, T. J. and Peters, D. P. C., Effects of climate change on phenologies and distributions of bumble bees and the plants they visit. Ecosphere, 2016, 7(3), e01267.

26. Herrera, C. M., Sanchez-Lafuente, A. M., Medrano, M., Guitian, J. and Rey, P., Geographical variation in autonomous selfpollination levels unrelated to pollinator service in Helleborus foetidus (Ranunculaceae). Am. J. Bot., 2001, 88(6), 1025-1032.

27. Zhang, Y. X., Hu, H. Y. and He, X. J., Genetic diversity of Urophysa rockii Uibrich, an endangered and rare species, detected by ISSR. Acta Botanica Boreali-Occidentalia Sinica, 2013, 33(6), 1098-1105.

28. Yun-Xiang, Z., Hao-Yu, H. U., Li-Juan, Y., Chang-Bao, W. and Xing-Jin, H. E., Seed dispersal and germination of an endangered and rare species Urophysarockii (Ranunculaceae). Plant Divers. Resour., 2013, 35, 303-309.

29. Bo, Z., Shijian, L., Li, S., Dafang, Z., Dehuai, W. and Shuangyan, X., Establishment and optimization of SCo T-PCR System of an endangered and rare species Urophysa rockii Ulbr. Mol. Plant Breed., 2016, 14(09), 2453-2459.

30. Jin-Yao, H. U., Dan, L., Xiao-Hong, J. and Ze-Yuan, S. U., A preliminary study on soil properties of Urophysa rockii community. J. Mianyang Normal Univ., 2010, 29, 72-75.
31. Ulbrich, E. Ranunculaceae novae vel criticae VIII. Notizblatt Des Königl Botanischen Gartens und Museums Zu Berlin, 1929, 10, 863-880.

32. Pengfei, B., Ting, T., Jinyao, H. U. and Wei, J., Flowering phenology and breeding system of an endangered and rare species Urophysa rockii (Ranunculaceae). Acta Ecol. Sin., 2018; http://dx.doi.org/10.5846/stxb201705160905.

33. Du, B. and Yang, F., Urophysa rockii Ulbr. a rare and endangered plant needs urgent conservation. Curr. Sci., 2010, 99, 419-420.

34. Dafni, A., Pollination Ecology: A Practical Approach, Oxford University Press, New York, USA, 1992, pp. 1-57.

35. Group, T. A. P., An ordinal classification for the families of flowering plants. Ann. Mo. Bot. Gard., 1998, 85(4), 531-553.

36. Wu, Z. Y., Lu, A. M., Tang, Y. C., Chen, Z. D. and Li, D. Z., The Families and Genera of Angiosperms in China, Science Press, Beijing, China, 2003, pp. 23-34.

37. Farkas, Á. and Orosz-Kovács, Z., Nectar secretion dynamics of Hungarian local pear cultivars. Plant Syst. Evol., 2003, 238, 5767.

38. Galloni, M. and Cristofolini, G., Floral rewards and pollination in Cytiseae (Fabaceae). Plant Syst. Evol., 2003, 238, 127-137.

39. Herrera, C. M., Components of pollinator 'quality': comparative analysis of a diverse insect assemblage. Oikos, 1987, 50, 79-90.

40. Herrera, C. M., Pollinator abundance, morphology, and flower visitation rate: analysis of the 'quantity' component in a plantpollinator system. Oecologia, 1989, 80, 241-248.

41. Schupp, E. W., Jordano, P., Gómez, J. M. and Janneke, H. R. L., A general framework for effectiveness concepts in mutualisms. Ecol. Lett., 2017, 20(5), 577-590.

42. Keys, R. N., and Smith, B. S. E., Pollination effectiveness and pollination efficiency of insects foraging Prosopis velutina in southeastern Arizona. J. Appl. Ecol., 1995, 32, 519-527.

43. Lehnebach, C. and Riveros, M., Pollination biology of the Chilean endemic orchid Chloraea lamellata. Biodivers. Conserv., 2003, 12, 1741-1751.

44. Zhao, L., Gong, J. Z., Zhang, X. H., Liu, Y. Q. and Ren, Y., Floral organogenesis in Urophysa rockii, a rediscovered endangered and rare species of Ranunculaceae. Botany, 2016, 94(3).

45. Silvana, M.-R., Fenster, C. B., Agnarsson, I., Skog, L. E. and Zimmer, E. A., Evolutionary breakdown of pollination specialization in a Caribbean plant radiation. New Phytol., 2010, 188, 403417.

46. Zhao, Y. L., A survey on the study of pollination biology of orchidaceous plants. Chinese Bulletin of Botany, 1994, 11, 27-33.

47. Waser, N. M., Chittka, L., Price, M. V., Williams, N. M. and Ollerton, J., Generalization in pollination systems, and why it matters. Ecology, 1996, 77(4), 1043-1060.

ACKNOWLEDGEMENTS. This study was financially supported by the National Natural Science Foundation of China (31170319), the Sichuan Provincial Key Laboratory for Ecological Security and Protection (ESP1413), and the Project of Mianyang Normal University (07119713), China.

Received 11 July 2018; revised accepted 13 March 2019

doi: $10.18520 / \mathrm{cs} / \mathrm{v} 116 / \mathrm{i} 12 / 2055-2062$ 